\title{
Bridging the Divide: Exploring the use of digital and physical technology to aid mobility impaired people living in an informal settlement
}

\author{
Giulia Barbareschi \\ UCL Interaction Centre \& Global Disability Innovation Hub, London, United Kingdom, \\ giulia.barbareschi.14@ucl.ac.uk
}

\section{Ben Oldfrey}

Global Disability Innovation Hub \& Institute of Making, London, United Kingdom, b.oldfrey@ucl.ac.uk

Long Xin

UCL Interaction Centre, London, United Kingdom, xin.long.18@alumni.ucl.ac.uk

Grace N. Magomere

Community Researcher, Nairobi, Kenya, gmagomere@gmail.com

Wycliffe A. Wetende

Community Researcher, Nairobi, Kenya, mzungureload77@gmail.com

Carol Wanjira

Community Researcher, Nairobi, Kenya

Joyce Olenja

School of Public Health, University of Nairobi, Nairobi, Kenya, jolenja@uonbi.ac.ke

Victoria Austin

Global Disability Innovation Hub, London, United Kingdom, victoria.austin@ucl.ac.uk

Catherine Holloway

UCL Interaction Centre \& Global Disability Innovation Hub, London, United Kingdom, c.holloway@ucl.ac.uk

\begin{abstract}
Living in informality is challenging. It is even harder when you have a mobility impairment. Traditional assistive products such as wheelchairs are essential to enable people to travel. Wheelchairs are considered a Human Right. However, they are difficult to access. On the other hand, mobile phones are becoming ubiquitous and are increasingly seen as an assistive technology. Should therefore a mobile phone be considered a Human Right? To help understand the role of the mobile phone in contrast of a more traditional assistive technology - the wheelchair, we conducted contextual interviews with eight mobility impaired people who live in Kibera, a large informal settlement in Nairobi. Our findings show mobile phones act as an accessibility bridge when physical accessibility becomes too challenging. We explore our findings from two perspective - human infrastructure and interdependence, contributing an understanding of the role supported interactions play in enabling both the wheelchair and the mobile phone to be used. This further demonstrates the critical nature of designing for context and understanding the social fabric that characterizes informal settlements. It is this social fabric which enables the technology to be useable.
\end{abstract}

CCS CONCEPTS

- Human-centered computing • Accessibility • Empirical studies in accessibility 


\section{KEYWORDS}

Wheelchairs, Mobile phones, Interdependence, Human infrastructure

\section{Introduction}

The World Health Organization estimate that there are approximately a billion people with disabilities who require access to appropriate assistive technology and this number is set to double by 2050 [80]. Assistive technologies (ATs) play a crucial role in the lives of people with disabilities and are necessary to be able to access essential services and participate in family and community life according to one's aspirations $[40,62$, $68,81]$. Although this is not often specifically mentioned, the large majority of people with disabilities will routinely use more than one assistive device in their everyday lives $[25,26]$. For example a person with a visual impairment is likely to use a white cane to navigate from their house to the office where they work and have a screen-reader, or an equivalent accessibility software, on their computer to be able to do their work once in the office [17].

Unfortunately, over $85 \%$ of people with disabilities (PWDs), the majority of which live in low-and-middle income countries (LMICs), don't have access to the assistive devices that they need [53, 82]. PWDs living in LMICs also face enormous challenges due to the inaccessibility of the built environment which, combined with systemic issues such as poverty and stigma, contribute to their persistent exclusion [33, 43]. In Kenya there are approximately 4.5 million people living with a disability (10\% of total population) [36]. The most prevalent form of disability is linked to mobility impairments [36]. Almost half of PWDs in Kenya are unemployed and $67 \%$ of PWDs, compared to $52 \%$ of non-disabled people, reported living below the poverty line $[49,50]$.

In recent years, mobile technology has emerged as an increasingly important form of AT for PWDs [6, 7, 24, $30,54]$. Mobile phones are far more ubiquitous in their coverage compared to other forms of technologye.g. the mobile penetration rate in Kenya for PWDs is $82 \%$ [28]. Recent research carried out in informal settlements has shown how the use of mobile technologies by PWDs is shaped by the social infrastructure (i.e. network of social interactions that are created across families and communities) [7]. Similarly, the framework on interdependence proposed by Bennett shows how the experience of disability is shaped by the complex and situational relationships that connect people and technology [10].

Interestingly, both the interdependence framework and the human infrastructure concept place significant emphasis on the relationship between PWDs, their social networks and AT but little attention is given to the interplay between multiple ATs, especially exploring the boundaries between physical and digital AT [10, $59,61]$.

In this paper we use the lens of interdependence and human infrastructure to understand the modalities in which people with mobility impairments who live in an informal settlement in Kenya use both their wheelchair and their mobile phones. Through a series of qualitative explorations, we examine how the boundaries and the relationships between these two different types of ATs shape people's experience of disability.

The contributions of this paper include:

1. The first known study comparing traditional and emerging technology use in informal settlements

2. An analysis of the simultaneous relations that exist in this context between people with mobility impairment, their support networks and the physical and digital assistive devices that they use

3. Further evidence of the role of the social network in enabling and amplifying the impact of technology in low resource settings.

4. Reflections on the role that mobile technology plays in bridging physical accessibility gaps

\section{Background}

This work builds on three different areas of research: understanding wheelchair use in low-resourced settings, exploring mobile technology use in informal settlements and the theoretical frameworks of interdependence and human infrastructure. 


\subsection{Wheelchair use in low-resourced settings}

The wheelchair represents an invaluable technology that can support people with mobility impairment in low-resourced settings to perform many everyday activities, access fundamental services and participate in family and community life $[14,63]$. When they have access to appropriate wheelchairs, people with mobility impairments have greater opportunities to access formal education and employment [44].

However, only $5-15 \%$ of mobility impaired people who live in low-resourced settings have access to appropriate wheelchairs [79]. The majority of wheelchairs available in low-resourced settings are provided by governmental organizations, charitable organizations and other international organizations [2, 15]. Unfortunately, many of the wheelchairs provided are donated by Global North countries and are designed for temporary use in hospital or other institutional settings - they neither meet the WHO guidelines nor the durability requirements of limited-infrastructure environments $[5,51,55]$.

Inaccessible infrastructures and informal road systems highly restrict the use of wheelchairs in low-resourced settings. For example, wheelchair users in South Africa were not able to push by themselves when trying to access formal healthcare services, on account of numerous geographical barriers such as mud, gravel, uneven roads and hills [77]. Similarly, wheelchair users in Thailand stated that moving around can be very difficult, even in one's own house due to the lack of space and the presence of various environmental barriers [38]. Without regular maintenance/repair services, wheelchairs in developing countries usually fail more quickly than their expected life span, which leads to adverse effects on social participation [71]. While more than half of participants in Tanzania were satisfied with the features of the wheelchairs, few were happy with follow-up services [3]. Similarly, a study in Zimbabwean found that wheelchair users showed high levels of dissatisfaction with wheelchair features, services, and the majority reported that wheelchairs did not provide effective mobility [78].

These studies indicate that, even when access to a wheelchair is possible the majority of users still encounter countless problems due to sub-standard devices, lack of services and inaccessibility of the built environment. However, few studies have looked at the specific situation of informal settlements where the lack of space and infrastructure might present additional barriers, but the larger availability of services compared to rural communities and the more flexible social system could support people with mobility impairments $[12,74$, 87].

\subsection{Mobile technology use in informal settlements}

A large part of the HCI research focusing on understanding how people access and use mobile phones in their daily lives has been mainly carried out in high-resourced settings [9, 21, 57, 70]. However, in recent years, a growing body of evidence has started to examine the unique social and infrastructural dynamics that shape the use of mobile phones in low resourced settings [4, 32, 54, 58].

The use of mobile technologies in informal settlements is still poorly understood. For example, we were only able to find eight studies that looked specifically at mobile phone use in informal settlements located around the area of Nairobi. Susan Wyche stated that the main problems which informal settlement residents in Nairobi experience when interacting with their phones are the prevalence of bad quality handsets, lack of money to afford airtime, charging fee, repair cost and fear of theft [83], which are similar to difficulties seen in rural Kenya [86]. ]. In spite of the financial burden, using mobile phones leads to diverse positive outcomes. Informal settlement residents appreciate their handset since it eases communication and improves employment opportunities [83].

The work by Sambasivan et al [60] shows that mobile phones have been leveraged by people in informal settlements to create and maintain networks that support both social and livelihood aspects of everyday lives. Particularly for younger users, the ability to access social media via mobile internet provides them with a space to express themselves and strengthen their social ties, but only with people who belong to the same "social class" [37]. Despite this limitation actively engaging in social media can still help young adults to increase their income [85]. Previous studies carried out in India have also shown that access to mobile phones and accessible platforms enabled people with disabilities not only to consume digital content, but also to 
create resources that could support other members of their virtual communities, potentially leading to empowerment $[75,76]$

Mobile technologies are also shown to be very useful in supporting the organizations of groups that could help tackle social challenges, such as safety and community health. Researchers involved in the project called Safe Mathare, leveraged the use of mobile technology to create a network of volunteers in the local community that could help patrol streets and escort women to ensure their safety when walking during the most dangerous hours of the day [29]. Furthermore, in a study by Perrier et al [56], ] a hybrid system was developed where automated SMS would be used to initially engage a large number of pregnant women in health related conversations which then linked to a local nurse to provide follow-up dedicated advice as required.

Mobile phones have also been used to engage local people in collecting data that can help better assess the problems affecting their communities. For example, researchers involved in [20] combined GPS data collected with data gathered via semi-structured interviews to understand how the lack of plumbing systems affected the water collection practices which are mostly carried out by women and young girls. Similarly, mobile devices have also been used to engage local residents in mapping geospatial data of informal settlements in the project known as "Mapping Kibera" which aimed to improve the provision of information and services in the area [39].

Outside of Nairobi, we also see efforts to understand the role of mobile technologies in informal settlements. Interestingly, De Souza e Silva [65] described the difficulties encountered by people in the Brazilian favelas in accessing and using mobile phones. The paper also reported some of the illegal practices that people will apply to access a mobile handset, highlighting the importance that mobile devices have for many slum dwellers [65]. Owning a mobile phone does not always translate in being able to access many mobile services. In informal settlement in Uganda for example, local youth has high prevalence of mobile phone ownership, but low access to internet and social media [69].

The role of mobile technology in empowering the most marginalised communities in low-resourced settings has received more attention in recent years. Scholars focusing on theoretical frameworks for ICT4D work have highlighted the importance of ensuring correct representation of specific groups of participants and their social contexts to ensure that we understand how technology can contribute but rarely forge development $[22,31,72,73]$. However, very little of this literature focuses specifically on people with disabilities living in informal settlements. In Colombia a group of researchers showed that a simple SMS service was implemented to distribute information and promote social interaction between caregivers of people with disabilities [8].

The only paper looking specifically at how people with disabilities in informal settlements use leverage mobile technology in their everyday lives was authored by Barbareschi et al [7]. Through their qualitative exploration, authors described how social connections shape independent, supported, dependent and restricted use of mobile technologies by people with visual impairment expanding on the concept of intermediated use proposed by $[27,59]$. The current study builds and expands the evidence presented by Barbareschi et al 2020. Besides analysing the relationship between the use of mobile technology and the individual's social network, the current study incorporates insights concerning a more 'traditional' assistive device such as the wheelchair. Our study shows how, despite the different nature of these products, the mobile phone helps the person extend the reach of the wheelchair by allowing them to tap on their social network and receive ad hoc help when needed. Furthermore, when looking at the stories collected from participants, it emerges how for visually impaired people the inaccessibility of mobile devices and services can sometimes be the cause of supported, dependent and restricted interactions. On the other hand, for mobility impaired people restricted and dependent interactions are almost always caused by the physical environment and, occasionally by the wheelchair, whereas the mobile phone is used as a tool to obtain the required support.

\subsection{Interdependence and Human infrastructure}

The concept of social and human infrastructure developed in ICT4D has its roots in the pioneering work on ethnography research by Star [66]. Star describes infrastructure as a relational property which is part of human organisation. Contrary to more traditional views, Star highlights how infrastructure is highly 
subjective and points out that "One person's infrastructure is another one's topic of difficulty". For example stairs can be seen as a means of accessing a building for a person without mobility impairment, the subject of work for an architect, and a barrier for a person who uses a wheelchair [66]. Most infrastructure is also hidden from view and Star draws attention to the importance of noticing all the hidden work done by marginalised actors who are perceived as "nonpeople" peripheral to the action, as forgetting their contribution often means failure of a system [66].

Sambasivan and Smyth [61] developed the concept of Human infrastructure specifically within the context of ICT4D. This complex web of people, environments, relationships and aspirations shapes how technology is used and often determines the success or failure of any technological intervention deployed in a particular context. Human infrastructures can also be empowered and amplified by technology which works as a catalyst of pre-existing social dynamics $[72,73]$.

Human infrastructure creates the system that enables intermediated technology use, where social connections are used to extend the reach of individuals who lack financial resources and literacy, digital or traditional, to directly interact with technology. These interactions are often made possible by the shared understanding of context that supports the creation of trust governing intermediated use [59,61]. Trust was also crucial for the type of 'beneficiary' and 'in-direct' interactions described by Ghosh et al [27] where users handed over their pass-books to Susu (savings) collectors in a microfinance scheme in Ghana or customers of M-banking agents in India allowed out of sight interactions to take place. On the other hand, PWDs might feel less confident in bestowing trust on strangers as being perceived as more vulnerable might make them more easily subjected to scams. For example, these 'dependent interactions' with strangers reported by visually impaired participants in Kibera were often undesirable and the trust gained with a few selected local operators had been built over a difficult process or trial and error [7].

Human interactions are also at the core of the interdependence framework for assistive technology recently proposed by Bennett et al [10]. The framework pushes back on the traditional idea that sees independence as the ultimate goal for ATs. It points out independence is a myth for everyone because "All people constantly rely on others, even if those others are invisible to us" [10,48, 64]. Similarly to human infrastructure the concept of interdependence focuses on relations, highlighting the interactions that take place between people and technologies and helps to reveal the hidden work done by people with disabilities. Furthermore, the interdependence framework helps to unpack the co-existing nature between relations and assistance and, by democratizing the concept of mutual reliance, challenges traditional ability-based hierarchies [10].

The interdependence framework has been widely used in HCI from defining opportunities for AI technologies that take into account how people with and without disabilities care of each other when completing tasks [11], to understanding the experiences of Uber and Lyft drivers when interacting with people who are visually impaired [19], and the dynamics created around the use of voice assistants in families with mixed visual abilities [67]. However, the framework has been rarely applied to low-resourced settings where social relations seem to play an even larger role in technology use. The only example was the study by Kameswaran \& Muralhidar [35] that showed how people with visual impairments in India have to carry out several "hidden actions" pre and post transactions due to the inaccessibility of mobile money services when paying for ride-hailing services. Furthermore, the interdependence framework has not been applied to understand how people navigate the boundaries between different ATs depending on the social and environmental context.

Therefore, this study aims to understand how the use of physical and digital devices by people with mobility impairment who live in the informal settlement of Kibera are shaped by the environment, the social connections and the human infrastructure that they live in.

\section{Methods}

\subsection{The study setting: Kibera}

Located only six kilometres away from the city centre, Kibera is the largest informal settlement in Nairobi and one of the largest in Africa. The informal settlements cover an area of 2.5 square kilometres, which is 
now all owned by the Government of Kenya. With the recent development of the economy in Nairobi, an increasing number of people from other tribes moved to Kibera for employment and the government allowed the settlement to grow [47]. The estimated population of Kibera varies according to different organisations because of the lack of reliable data. The Kenyan government estimated the total population to be around 200,000 [36]. UN-Habitat suggested the total Kibera population may be much higher between 350,000 to one million, while the International Housing Coalition give an estimate of more than half a million people [52].

Similar to other informal settlements, Kibera lacks many basic services such as drainage systems, water facilities and access to electricity. It also suffers from high crime rates and sever pollution [52]. Despite recent efforts from international development programs the conditions of roads and other environmental infrastructure is poor and problems with overcrowding are likely to severely affect wheelchair use [52]. However, residents in Kibera have often access to better services compared to people living in rural areas $[74,85]$.

\subsection{Study procedure}

The study featured a series of semi-structured interviews to understand usage of wheelchairs and mobile technologies in the daily lives of participants. Ethnographic observations were carried out with participants in the community to provide contextual information to the interviews.

\subsubsection{Participants}

The study participants were mobility impaired people living in Kibera, Nairobi. To qualify for participation, participants were required to be a mobility assistive device user (such as wheelchair or tricycle) and have experience of using a mobile phone (Table 1). Eight participants (4 females and 4 males, aged 30-63) were recruited in this study. Participants were approached through the Kibera Disability Group, a local organization supporting residents with different kinds of disabilities. Among these 8 participants, 4 participants were either born with a mobility impairment which affected both their legs (P1 and P4) or they acquired it at a very young age due to polio (P7) or another condition (P2). On the other hand, P3 and P5 acquired thoracic spinal damage later in life as a result of an accident and P6 underwent amputation due to vascular issues. Two participants were tricycle users and the other six were wheelchair users. Six participants were mobile phone owners, whereas two had access to a shared mobile phone through a member of the family. None of the participants in this study reported any significant impairment of the upper limbs, which could affect their ability to interact with a mobile phone

\section{Table 1 Participants' characteristics}

\begin{tabular}{lllll}
\hline Participant ID & Gender & $\begin{array}{l}\text { Type of } \\
\text { wheelchair }\end{array}$ & $\begin{array}{l}\text { Type of } \\
\text { mobile phone }\end{array}$ & Occupation \\
\hline P1 & Male & Tricycle & Button phone & Self-employed (shoe maker) \\
P2 & Female & $\begin{array}{l}\text { Folding frame } \\
\text { wheelchair }\end{array}$ & $\begin{array}{l}\text { Touchscreen } \\
\text { phone }\end{array}$ & Unemployed \\
P3 & Male & $\begin{array}{l}\text { Folding frame } \\
\text { wheelchair }\end{array}$ & Button phone & $\begin{array}{l}\text { Self-employed (bracelet } \\
\text { maker) }\end{array}$ \\
P4 & Female & $\begin{array}{l}\text { Folding frame } \\
\text { wheelchair }\end{array}$ & $\begin{array}{l}\text { Button phone } \\
\text { (sharing } \\
\text { phone with } \\
\text { her husband) }\end{array}$ & $\begin{array}{l}\text { Self-employed (grocery } \\
\text { seller) }\end{array}$ \\
\hline & & & & \\
\hline
\end{tabular}




\begin{tabular}{lllll}
\hline Participant ID & Gender & $\begin{array}{l}\text { Type of } \\
\text { wheelchair }\end{array}$ & $\begin{array}{l}\text { Type of } \\
\text { mobile phone }\end{array}$ & Occupation \\
\hline P5 & Female & $\begin{array}{l}\text { Folding frame } \\
\text { wheelchair }\end{array}$ & $\begin{array}{l}\text { Button phone } \\
\text { (sharing } \\
\text { phone with } \\
\text { her father) }\end{array}$ & Unemployed \\
P6 & Female & $\begin{array}{l}\text { Folding frame } \\
\text { wheelchair }\end{array}$ & $\begin{array}{l}\text { Touchscreen } \\
\text { phone }\end{array}$ & Unemployed \\
P7 & Male & Tricycle & $\begin{array}{l}\text { Touchscreen } \\
\text { phone }\end{array}$ & Self-employed (shoe maker) \\
P8 & Male & $\begin{array}{l}\text { Folding frame } \\
\text { wheelchair }\end{array}$ & $\begin{array}{l}\text { Touchscreen } \\
\text { phone }\end{array}$ & $\begin{array}{l}\text { Self-employed (secondhand } \\
\text { clothes seller) }\end{array}$ \\
\hline
\end{tabular}

\subsubsection{Materials}

Interviews were audio recorded using a portable Dictaphone. A second back up recording was made with a mobile phone to prevent loss of data. Videos and photographs were collected during observations using a GoPro camera.

\subsubsection{Data collection and analysis}

The data collection team consisted of a local guide, three researchers, the second and third author from the Global Disability Innovation Hub and the UCL Interaction Centre, and the fourth author a community researcher from Nairobi, and a wheelchair trainer that participants were familiar with. In this qualitative study, we collected data both through semi-structured interviews and ethnographic observations in the community. The majority of participants (7/8) felt more comfortable being interviewed in Swahili rather than English. The information sheet and consent forms were presented to participants in English with Swahili translation. After obtaining written consent, the interviews were conducted in Swahili by the local researcher ( $4^{\text {th }}$ author) with the assistance of a Kiberan resident, who was hired as a guide. The other researcher took notes and asked follow-up questions in English when it was necessary. Interviews took place in participants' homes and lasted for about 60-90 minutes each. Questions focused on four different areas: participants' lived experience in Kibera, their wheelchair use experience, their daily mobile phone usage patterns and the challenges encountered when using these two assistive tools. During ethnographic observations participants showed us how they moved in the home. This included transferring to and from the wheelchair where appropriate, navigating the areas around their houses to the closest main roads and reaching their place of work or other significant locations that they mentioned in the interview. Participants also illustrated how they used mobile phones to manage their business and reach out for the help of friends and family members. Participants were compensated $2000 \mathrm{KSH}$ for their time.

The collected data included interviews recordings, supplemented by digital photographs and videos collected during ethnographic observations of participants using their wheelchairs and mobile phones, and field notes from the researchers. The audio recordings were transcribed in Swahili and translated to English. Thematic analysis [18] was carried out primarily by the first author with the aim of drawing out the reciprocal and wider relational aspects that govern the use of different ATs in the everyday lives of mobility impaired people in Kibera. As the analysis progressed, themes were discussed amongst the members of the research team to ensure that the interpretation matched the cultural context of participants.

\section{Findings}

In the current section we present themes formulated as a result of the analysis conducted. 


\subsection{The wheelchair use experience}

\subsubsection{Wheelchairs as mobility enhancers}

The wheelchairs or tricycles (Figure 1) used by participants were primarily supplied by hospitals, disability groups and churches free of charge. Only one respondent's wheelchair was bought by her mother and she did not know the cost. The introduction of wheelchairs into people's lives had a definite impact on their level of mobility. Interviewees stated that before having access to a wheelchair they were often unable to leave the house by themselves as had to be carried by caregivers or crawl which was extremely difficult to do outside.
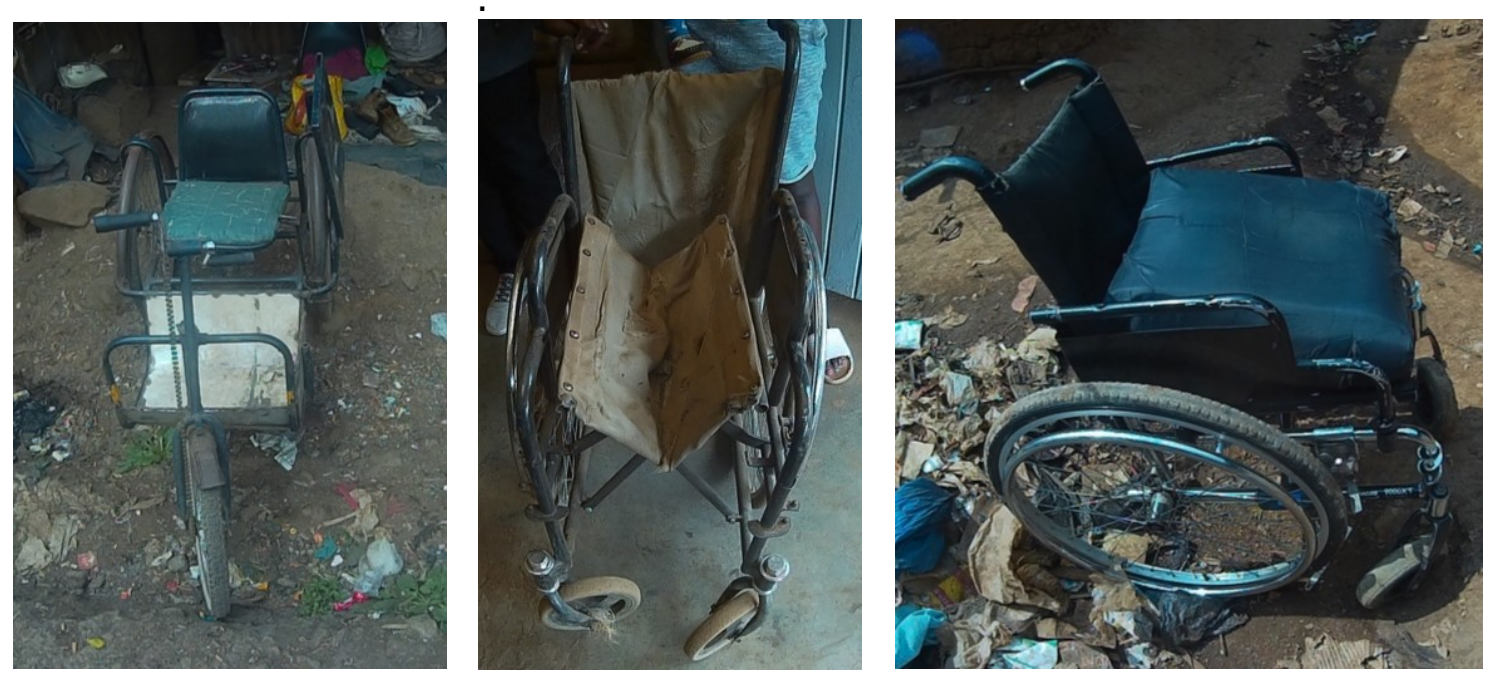

Figure 1 Examples of wheelchairs used by participants in the study from the left (P1, P6 and P8)

P04: "My mother took care of me there [when I was a child], so she took care of me and she used to carry me on her back and take me for physical therapy to the hospital and back to the house, so she did this for a very long time."

P01: "That time I did not have a wheelchair, that time I was scrolling [crawling on the ground] ... that time I came to live here, it was very bad because there was mud allover".

Due to the mobility granted by the wheelchair, participants could travel to visit families and friends and run businesses to support their livelihood. However, this meant that breakages and failures of the wheelchair could severely impact the person's life.

P03: "it [the wheelchair] has helped me because, if for example I want to go and greet a friend then I sit on it and go chat and come back, so I see they did a good thing because if I go without it is very tiring so I just sit and go"

P07: "Mostly it [the wheelchair] is the one that helps to go and get materials, but when it is broken down everything stops, it is not only the wheelchair, I cannot go to bring my business materials"

Wheelchairs also help users to make longer trips outside Kibera and engage in different kinds of activities. Interestingly, wheelchairs did enable people to travel independently, but they also helped users to receive assistance to a level that they felt more comfortable with. 
P04: When I am going to far places like hospital, or to see my friends, I ask someone to come and pick me [up] to go with it, it is important for me, but if I don't have this one [touches her wheelchair] I cannot go

$$
\text { far" }
$$

P02: "When I move and someone pushes me, it helps because they cannot be carrying me to move"

\subsubsection{Barriers to wheelchair mobility}

Although crucial for their mobility, all participants encountered numerous challenges using their wheelchairs effectively around Kibera. Most participants lived in small basic accommodations and to save space in the house, they had to keep the wheelchair folded when not in use. For most, unfolding their wheelchair and transferring to it was already challenging and participants who lived alone needed to call a friend or a neighbor for help. Nevertheless, the most significant challenge they encountered was to get from their house to the main road in Kibera.

Most of the side roads that connected participants' houses to the main road were muddy, narrow, rough, and therefore inaccessible (Figure 2). Open drains carrying off waste cut across these roads, and, when it rained, the situation became worse. Even P05, who lived in better housing condition as part of an upgrading programme run by the UN-Habitat, needed help to get out of her house since a step blocked her way. Given these multiple environmental barriers, the wheelchair offers limited assistance. The only solutions for participants is either to have the wheelchair carried outside by one person as they crawled to the main road, or to be carried by others, as the terrain can make it impossible for the wheelchair to be pushed.

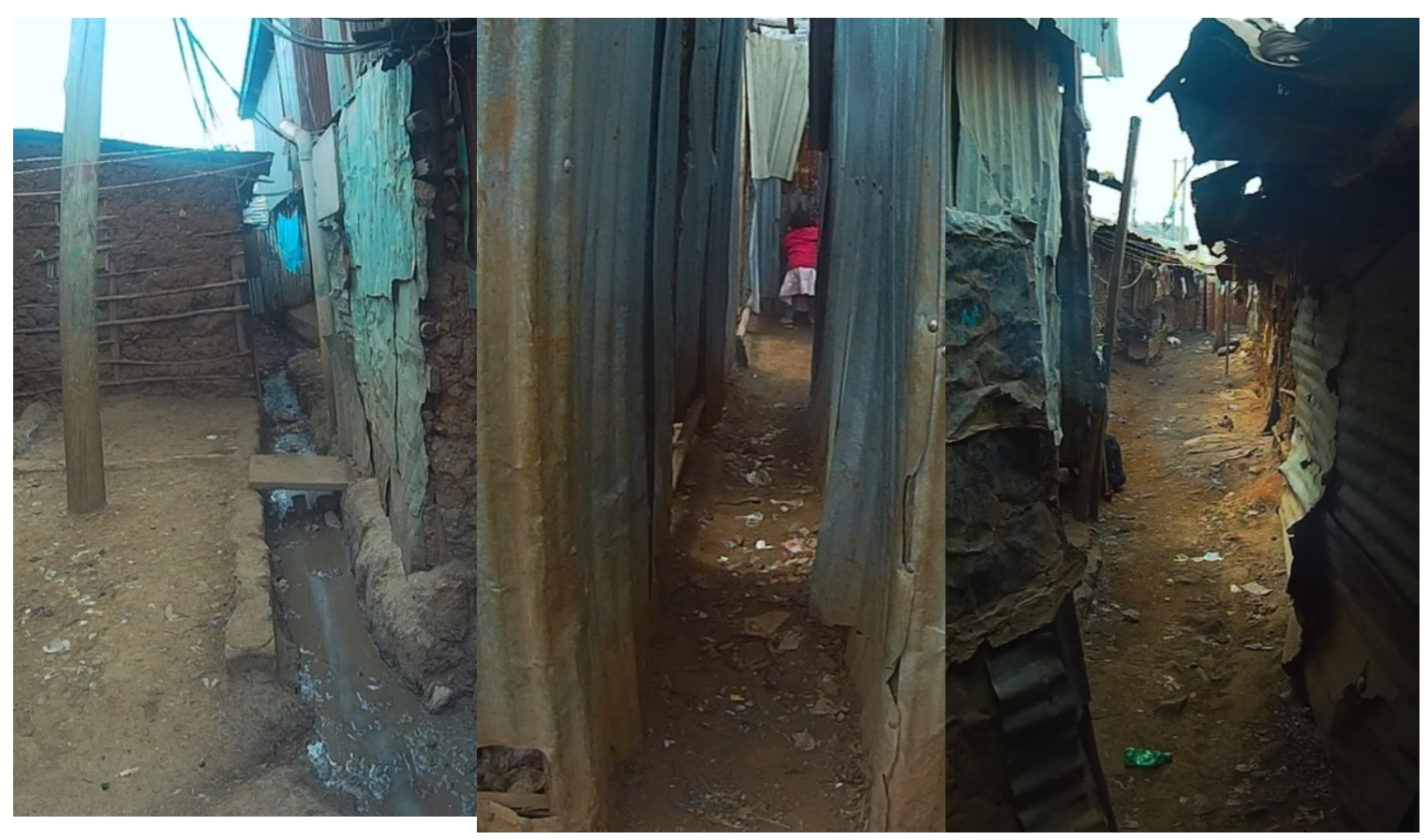

Figure 2 Three examples of side streets commonly found in different parts of Kibera

P06: "Since the wheelchair cannot come up to here, I wear slippers on my hands and there are things I wear on my knees and I crawl up to where you have seen the wheelchair".

P02: "From the main road up to here, my sister and my brother they have to carry me and one carries the wheelchair" 
Even on the main road, many participants are unable to push themselves independently and they require assistance due to the difficult terrain. Tricycle users were able to push themselves independently when the road condition is good. However, assistance was still needed on sloped surfaces, uneven and graveled roads or after heavy rains.

P01: "This vehicle of mine is the one I use, I roll down with it and when I reach an uphill I ask for help to go over it and then I proceed slowly; the only challenge is where there is a hill"

If no one was around to help, participants could do nothing but wait or exhaust themselves attempting to overcome the obstacle. Some people stopped by and offered help, however, they often charged money in return for assistance. Similarly, local bus drivers often charged extra to wheelchair users as the wheelchair regarded as a luggage or it had to occupy a second seat. For some people paying meant sacrificing money for their basic needs.

P03: "This vehicle if you tell me to push it up to town I will have to be asked for money and that would mean the money for my vegetables and cooking oil is the one I will end up spending by going to town yet I don't have"

Apart from the increased expenditure, being assisted when travelling also made participants feel that they have less privacy due to the fact that another person, often a stranger, would know where they were going and what they wanted to do.

P04: "You see you don't have any private life because there is always someone supporting you, as a girl, we have privacy problems, you cannot do some things because there is that person who is pushing you, you are fearing, yes, like you want to go somewhere, you want to go alone".

\subsubsection{Challenges with maintenance and reparability}

Most of the wheelchairs used by participants in the study were in poor condition. For example, P06 stated that she rarely uses her wheelchair currently because she doesn't trust its robustness. However, repairing a wheelchair is Kibera is challenging. Firstly, payment for repairs is a burden. Depending on the broken part, payment for repairs ranges from hundreds of Kenyan shillings to thousands of Kenyan shillings (KES). The average income in Kibera is 3977 KES per person per month [23]. Since the majority of participants were unemployed, wheelchair repairs were an unaffordable expenditure for them. When users lacked money to repair the wheelchair, they faced considerable challenges accessing basic facilities and services.

P04: "If it [the wheelchair] breaks down it can be very hard for me and I would face many challenges because it will not be easy to go to anywhere and even to go to the toilet that can cause a lot of problems".

Additionally, it is difficult to find a professional technician in Kibera who is capable of repairing wheelchairs. Repairs of wheelchair are mostly done in welding or bicycle repairs shops. These informal repairers sometimes lacked capability to repair the broken wheelchair or had no appropriate replacement for it. As purchasing a new wheelchair is impossible for most people, in case of unrepairable breakages, the only thing participants could do is wait in the hope of being given a new one, knowing you "You may get it or you might not get it" (P05).

\subsection{The mobile phone use experience}

\subsubsection{Mobile phones as community connectors}

Half of the participants had button phones with limited internet access. They primarily used the phone to call family and friends. The main purpose of these calls is to ask for assistance "if I have a problem or I want something" (P06). For example, if participants need water or food when staying alone in the house, they would call others to bring it to them. With the assistance of a mobile phone, mobility impaired residents in 
Kibera meet basic physiological needs from the perspective of Maslow's Hierarchy of Needs [42]. Additionally, participants called their friends when they needed help to use their wheelchair. Other than asking for assistance, participants also made calls to keep in touch with family and friends, to strengthen existing social connections or create new ones, and to engage with support groups that brings together PWDs in Kibera.

P03: "It is good because I talk with my friends, people like you, because if it were not for the mobile phone would we have got to know each other?"

Participants who are self-employed also use the phone to contact customers, suppliers and to manage day to day business.

P07: "I can call my customers, I can communicate with them, and someone can leave for me a job and go and come back later so I can call them later".

Participants who owned touchscreen phones with internet access enjoyed more advanced features including video chat and use of social network sites to chat with friends, play games as well as browse the news.

P06: "When I wake up in the morning and after breakfast I go to WhatsApp to see those who have greeted me, I also respond by greeting them, after I have seen, I close again and I start playing games, I go to

Facebook at night".

These activities on mobile phones help mobility impaired people to maintain and strengthen relationships with their close and larger social circles. Furthermore, mobile phones were a source of entertainment in participants' daily lives, with some participants playing games and betting on local and international football. Taking photos is another function that brought happiness to people - they took photos of themselves and families to store memories. Sending photos to relatives living in other parts of the country also helped to maintain bonds with people that the participants were otherwise unable to see.

P07: "For example I have a baby in my home [family who lives away from the participant], she was born when I am here, so I requested to post to me, to take a picture and post it"”

If the participant's phone lacks a camera or access to the internet, people rely on their friends and families to be able to access these features. For example, P04's mobile phone does not have a camera, so she regularly asks her friend, who has a better mobile phone, to send and receive photos from her daughter who lives in a different part of the country. P04 said that every time she sees the photos of her daughter on the phone, she feels happy. In addition, mobile phones helped participants to search for employment and other opportunities in their communities.

P05: "If I want a job somewhere, I could call someone and he or she could tell me there is a work opportunity so I should prepare since they will be coming to pick me [up], then I will have to be ready."

Mobile phones also supported participants to manage their finances through the use of the mobile money service M-Pesa, which is ubiquitous across Kenya. M-Pesa allows people to deposit, receive and send money using SMS text message, so works on button phones with no requirement for internet access [34, 41, 45, 50]. The services is used frequently by all participants for various purposes from paying people for goods and services, to receiving customer payments.

However, money withdraw can be a problem for participants, as the withdraw service is only provided by specific agents. Some people, such P02 could gain assistance from a friend or relative, whereas others are simply unable to access this service. 
P03: "For me that I cannot [access the withdrawal service], now even if I deposit or you send me, who will go to withdraw for me, if someone wants to give me it is better to give cash, because I cannot go to withdraw"

\subsubsection{Barriers to mobile phone use}

Although mobile phones provide important support to participants in various activities, the use of a mobile phone increases people's living costs. Participants generally spent 20KES a day, 100KES weekly on airtime for voices calls and text messages. For internet users, the cost could increase up to 200KES to 250 KES a week. Because of the low rate of availability of electric in house, some participants needed to pay around 10 KES for phone charging, which is equal to the price of a piece of chapati (the most common bread) in Kibera. Furthermore, mobile phones of mobility impaired people were at a higher risk of being damaged as a results of the difficulties navigating the inaccessible environment.

P04: "I fell down by accident and I fell on it, it got spoilt. There are many [occasions where] because of my walking and sometimes falling, sometimes I fall and maybe it is in my pocket, when I fall on the side the phone is it breaks".

Mobile phone repairs were possible but their cost ranged from hundreds to thousands of Kenya shillings. For this reason, participants often preferred to buy a new mobile phone instead of repairing the broken one, since repairs were deemed unreliable and relatively expensive making a new device more cost-effective. (The cost of mobile phones owned by participants in the study ranges from 1500 KES to 5000 KES).

P01: "I consider to repair or to buy another phone and when you repair the repair does not last, they repair with cheap components that does not last long, so I will have lost money, so I decided to look for money and look for a good phone that can help me".

However, the majority of participants could not afford to buy a new phone shortly after the previous one broke. They had to save money and stay with a broken mobile phone, which negatively impacted their day to day life. To get a new phone as soon as possible, participants might purchase a cheap phone of low quality that was more likely to break down, which would result in a vicious cycle.

Mobile access is so important to P1 that if his mobile were to break, get lost or stolen "I will try in all ways even if it means borrowing money to buy another one" as he cannot live without mobile phone. To address the problem of no mobile phone to use, some participants share mobile phones with their family members. While shared use can provide temporary access to mobile phones, it leads to other problems such as inconvenience and lack of privacy, as participants could only use mobile phones when the relative who owned it was around.

P05: "You know he always uses his phone to make phone calls and I can't ask him to lend me his phone."

When the mobile phone is shared, every voice call and text message made is known by the owner. Even personal exchanges to friends and other family members, which makes participants feel very uncomfortable. Finally, some participants can only make use of certain mobile services but not others, due to their lack of digital or traditional literacy. Many participants don't use features as they have not "been taught" (P05) and they fear they "might spoil it [the mobile phone]" (P05). Other features, such as cameras were unused (P3) and whilst people interacted on social media, often they consumed rather than created content, as participants like P7 "don't know how to write posts".

\subsection{Social support in Kibera}

Besides the assistance provided by tools such as wheelchair/tricycles and mobile phones, mobility impaired residents received a lot of support from close community as well. Due to the inaccessibility of most of the 
local infrastructure, it was often thanks to the assistance from the community members that participants could access food, water and even electricity without charge.

P06: "I got support from a friend, she used to come visit me, sometimes she brings me food, sometimes clothes, like there was a time I was sick, she used to take me to the hospital and take me for shopping"

Social connections could also help people like P03 to grow their own business business. He is a bracelet maker, but due to his mobility impairment, he can rarely move outside to promote his products. However, his business grew thanks to the advertisement of children who live in his area.

Although stigma of the disability still exists in communities, the majority of participants feel that they are currently living within a friendly and supportive community.

P01: "Many of them we are used to one another, they don't look at me as a disabled person, so they just look at me as normal"

The local disability groups also offer great help to mobility impaired residents. There are many local disabilities groups in Kibera, and almost all participants in this study (but P5), are registered with one or two of them. In these groups, participants meet more people with similar or different of disabilities which make them feel less lonely. Participants also leverage local groups to receive more information about their rights as PWDs. Finally, groups can also provide financial assistance such as loans to start a business and offer mobility assistive tools to people who need them.

P07: "They (the disability group) used to support us, like you know I am a shoe repairer, and you want loan to buy your staff to boost business, they give you but you don't pay back, so they used to give us like fifty thousands and you don't pay back."

Although participants value the support of others, they are also proud of their independence which is often linked to their ability to have a steady income.

P04: "If I don't do my business, his (husband) income cannot meet my needs, and I have to depend on myself like a woman, so it is a must that I do my business, it is the one supporting me."

\section{Discussion}

Our research has shown that mobile offers a bridge across the physical barriers faced by wheelchair users living in Kibera. However, this bridge is only possible through the social network which exists to enable supported interactions (see below). We represent this model in Figure 3 and further explore these links in through the lenses of interdependence and human infrastructure. 


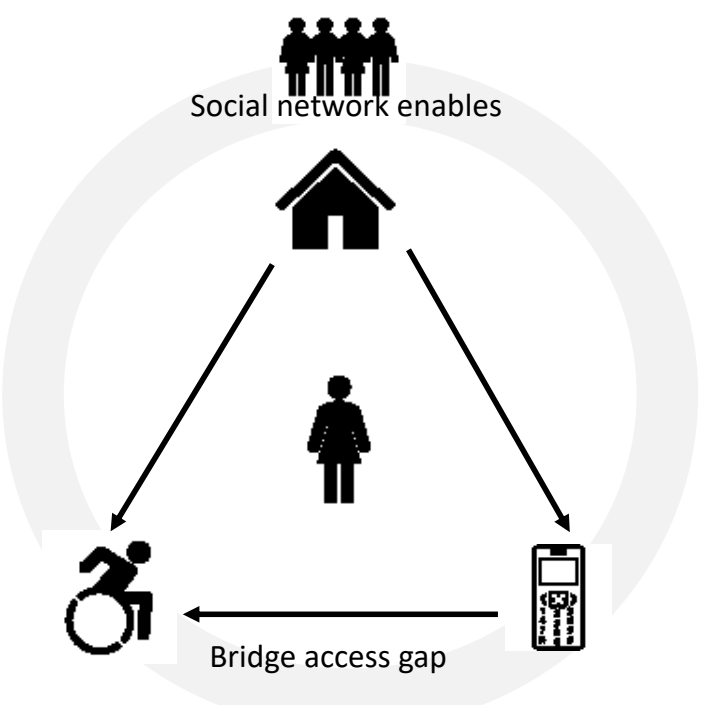

Figure 3: The physical and economic characteristics of Kibera restricts the use and impact of both the wheelchair and the mobile phone. However, the support of the Kibera social network unlocks the potential for mobile to bridge the physical accessibility gaps in Kibera for wheelchair users

\subsection{Interdependence and human infrastructure}

Despite their differences in scope and application, both the Human infrastructure and the Interdependence framework highlight how the experience of disability or technology use happen in a vacuum [10, 61]. Both of these experiences are shaped by a wide web of relationships and interactions between people that determine how PWDs create access for themselves and other and how technology is used in different contexts $[10,61]$. However, these dynamics of interdependence and human infrastructure are often determined by the social and physical context in which actions take place [16, 17].

Our study shows that the unique characteristics of the informal settlement of Kibera play a great role in the experiences of mobility impaired people, shaping the use of physical and digital ATs, and the way in which people access social support in their daily lives.

Using the lens of human infrastructure, a recent study of mobile phone use by visually impaired people in informal settlements found new types on interactions, which included - dependent, restricted and supported interactions [7]. In the current study we again see these interaction types related to mobile phone use as well as when using a wheelchair. However, some interactions are more prevalent for physical and others for digital technologies. Supported interactions - which are defined as being enabled by the community - occurred most frequently when interacting with the physical technology e.g. when people needed help getting their wheelchairs out of their home [P02], or help being pushed up a hill [P06]. Restricted interactions - which are characterized by exclusion - existed across both physical and digital domains. Mobile phone features were often unused due to cost and a lack of digital skills. This finding is in keeping with the previous study of VIP and mobile phone use [7].

The harsh physical environment prevented people from being able to reach different areas, resulting in restricted interactions with the wheelchair and then ultimately between the person and the world. These barriers could occasionally be overcome with the help of others. However, on some occasions this support came at a monetary cost and required the interacting with strangers and hoping they would help. This type of interaction is similar to what was previously described as a dependent interaction [7, 27]. Dependent interactions are built on trust. Previous research has shown how trust is built between say a shopkeeper and a visually impaired person to the point the visually impaired person will hand over their phone and passwords to allow the shopkeeper to top up their bank account or phone [7, 27]. This level of trust was not needed for 
wheelchair users when interacting with their mobile phones, however it was needed when venturing out in their wheelchairs. Then they would need to pay, and trust, a person to push them up the hill for example.

When looking at our findings through the lens of the interdependence framework [10] is it possible to see how the relations that occur around assistance are situational and people have often different roles depending on the circumstances. For example P4 could receive physical assistance for various tasks from her husband but she was also very determined to support herself and her family through her business as a grocery seller. Although the husband might help her carry her goods to the stall she would bring home money that would be used to support the family.

Even within the immediate moment of receiving assistance, participants also made both visible and invisible contributions that enable them to create access for themselves [10,64]. For example, when participant were pushed outdoor by a stranger they often were asked to pay some money in return. On the one hand, this made the mobility impaired person the recipient of assistance. At the same time, the act of paying also makes the non-disabled person a beneficiary as they received money in exchange for their help as the wheelchair users used their personal finances to create access.

Another example of simultaneous relation and assistance emerges from the world of P5 when she states that she cannot ask her father to access his phone as he is making calls when he returns from work. The power dynamic embedded within the bond between father and daughter makes her request more difficult that it would potentially be if the owner of the phone was a close friend. Her inability to have access to the phone also made the participant frustrated in a way that was similar to what was observed by Storer et al [67] when members of the family experienced tensions over the different uses of voice assistants.

The relations that people created within the social structure also show how, despite the difficulties they encounter participants are able to challenge traditional ability based stereotypes. Through their work, their activism within the support groups they engage with and their active roles in their family, the wheelchair users we interviewed were people who gave to society as much as they receive from it.

\subsection{Contrasts and connections between physical and digital devices}

The experience of use of both wheelchairs and mobile phones highlight the value of these to different technologies and they expose the different mechanisms of use. Wheelchairs were difficult to use in Kibera largely due to the harsh environment. This resulted in people needing help to overcome barriers such as irregular ground, steps and hills. These obstacles often happened at interfaces, points of transition between different parts of the environment such as door steps or side streets connecting participants' houses to the main road.

Mobile phones offered a bridge for some of these accessibility issues. They allowed people to call for assistance when needed and reach friend or a neighbour that could help them overcome these barriers and reach a point where they could use their wheelchairs. Communication at a distance also means that whoever is standardly required to help the person is able to confidently move out of range of verbal communication. Assistance can be requested at any point. This is hugely enabling for both parties - reducing constraints on activity and reducing the likelihood that urgent assistance will not be forthcoming when important. This helps to reduce anxiety levels for both parties.

The harsh environment of Kibera meant both types of technology necessitated constant repair, however these were handled differently, and we felt these differences were worthy of exploration.

Repair of the mobile phone was mostly deemed to be not cost-effective and instead people would save for a replacement phone. The repairs available for phones were mostly distrusted - due to a plethora of sub-quality parts on the market, which were still sold at high prices. These difficulties with mobile phone repairs are in line with some of the difficulties previously described by repairers themselves in both Kenya and Bangladesh $[1,84]$.

However, participants felt differently about their wheelchairs. For example, no one mentioned that they would buy a new wheelchair, it did not seem to occur to people that this would be possible. Due to the high strains placed on the wheelchairs by the difficult environmental conditions, even most minor breaks could render them unusable. According to the WHO all assistive technology needs to be manufactured with parts 
that can be repaired, maintained or replaced locally [80]. Unfortunately, in part because nearly all wheelchairs were manufactured in other countries, maintenance and repair was also really challenging [46]. Across the participants, wheelchairs were taken for major repairs (ie.welding) 3-5 times before the device was abandoned for good. This means that the majority of the useful life of the wheelchairs is only as a result of repair - a repair that is conducted in the community for a fee rather than being part of the service provision model [13].

Another factor that played a role in the attitude that participants had towards repairs and replacements was the different ways in which devices were acquired. Whereas mobile phones were devices that people bought for themselves, wheelchair had to be provided via charitable institutions or disabled people organizations. This also gave the two devices different values in the eyes of participants as the first one could be substituted in case of breakages, albeit at a high personal cost, whereas the latter had to be preserved at all cost.

\subsection{Implications for future $\mathrm{HCl}$ research}

The findings from the current study, together with other similar work such as the one carried out by Barbareschi et al [7] are helping to shape the future HCI, ICT and AT work in informal settlements. Both studies show how the use of physical and digital technologies is shaped by unique contextual factors of slum communities such as the poor physical infrastructure, the availability of services (such as mobile repair shops and support groups for people with disabilities), the dynamic network of social relationships and the experience of disability. This highlights the importance of expanding this research to the use of digital and physical technologies by people with disabilities living in informal settlements. Future work should seek to include people with different kinds of disabilities, such as hearing and cognitive disabilities, to develop a more comprehensive understanding and develop adequate solutions. Furthermore, we believe that comparison of studies conducted in different countries could help identify common elements that could be addressed by similar design solutions while highlighting unique cultural elements that might require customization. Our study also supports previous findings from Wyche $[84,86]$ showing how, in contrast with the culture of disposability common to many high income settings, reparability is crucially important for users of physical and digital technologies in less resourced settings and should be incorporated in the design of future devices.

Our insights show that future work must explore how to build confidence in mobile use as well as improve the physical and digital infrastructure of places such as Kibera. As physical infrastructure upgrades can take decades, it would seem important for the HCI community to take on with earnest the challenge of ensuring we continue to develop insights and practices which enable people using what might be considered outdated technology in some places - a button phone - to be able to fully use the technology and have the confidence to upgrade to a smartphone when they can afford to do so.

\section{Conclusion}

We have investigated for the first time the ways in which wheelchair users use their traditional assistive technology - their wheelchair and their digital link to the world - their mobile phone. We have done this in a specific context - in an informal settlement in Nairobi. Our investigation has shown there are key differences in how people are able to use their technology, with their social network being a key enabler for both mobile and wheelchair use. A barrier which cut across both technologies was the robustness of design for the environment. This necessitated frequent costly repairs of wheelchairs and replacement handset devices following a period of saving. We demonstrate how mobile phones act as a bridge across the physical accessibility divide, but also highlight the lack of confidence participants had in using their mobile phone fully.

\section{ACKNOWLEDGMENTS}

We would like to thank all of the study participants for their time and enthusiasm in the project. Additionally, we are immensely grateful to Motivation Africa (https://www.motivation.org.uk/kenya) for their support in study recruitment. The research in this paper was made possible by funding from the UK Department for 
International Development through the AT2030 Programme (www.AT2030.org) which is led by the Global

Disability Innovation Hub (www.DisabilityInnovation.com).

\section{REFERENCES}

[1] Ahmed, S.I., Jackson, S.J. and Rifat, Md.R. 2015. Learning to Fix: Knowledge, Collaboration and Mobile Phone Repair in Dhaka, Bangladesh. Proceedings of the Seventh International Conference on Information and Communication Technologies and Development (New York, NY, USA, 2015), 4:1-4:10.

[2] Amos G. Winter, V. 2006. Assessment of Wheelchair Technology in Tanzania. International Journal for Service Learning in Engineering, Humanitarian Engineering and Social Entrepreneurship. 1, 2 (Sep. 2006). DOI:https://doi.org/10.24908/ijsle.v1i2.2085.

[3] Amosun, S., Ndosi, A. and Buchanan, H. 2016. Locally manufactured wheelchairs in Tanzania-are users satisfied? African health sciences. 16, 4 (2016), 1174-1181.

[4] Anwar, M. and Johanson, G. 2015. Mobile Phones and the Well-Being of Blind Micro-Entrepreneurs in Indonesia. The Electronic Journal of Information Systems in Developing Countries. 67, 1 (2015), 1-18. DOI:https://doi.org/10.1002/j.1681-4835.2015.tb00481.x.

[5] Armstrong, W., Reisinger, K.D. and Smith, W.K. 2007. Evaluation of CIRwhirlwind wheelchair and service provision in Afghanistan. Disability and rehabilitation. 29, 11-12 (2007), 935-948.

[6] Barbareschi, G., Aranda Jan, C., Nique, M., Ramos Barajas, F. and Holloway, C. 2019. Mobile Phones as Assistive Technologies: Gaps and Opportunities. (2019).

[7] Barbareschi, G., Holloway, C., Arnold, K., Magomere, G., Wetende, W.A., Ngare, G. and Olenja, J. 2020. The Social Network: How People with Visual Impairment use Mobile Phones in Kibera, Kenya. Proceedings of the 2020 CHI Conference on Human Factors in Computing Systems (Honolulu, HI, USA, Apr. 2020), 1-15.

[8] Barlott, T., Adams, K., Díaz, F.R. and Molina, M.M. 2015. Using SMS as a tool to reduce exclusions experienced by caregivers of people with disabilities in a resource-limited Colombian community. Disability and Rehabilitation: Assistive Technology. 10, 4 (Jul. 2015), 347-354. DOI:https://doi.org/10.3109/17483107.2014.974223.

[9] Bayor, A.A. 2019. HowToApp: Supporting Life Skills Development of Young Adults with Intellectual Disability. The 21st International ACM SIGACCESS Conference on Computers and Accessibility (Pittsburgh, PA, USA, Oct. 2019), 697-699.

[10] Bennett, C.L., Brady, E. and Branham, S.M. 2018. Interdependence as a Frame for Assistive Technology Research and Design. Proceedings of the 20th International ACM SIGACCESS Conference on Computers and Accessibility (Galway, Ireland, Oct. 2018), 161-173.

[11] Bennett, C.L., Rosner, D.K. and Taylor, A.S. 2020. The Care Work of Access. Proceedings of the 2020 CHI Conference on Human Factors in Computing Systems (Honolulu, HI, USA, Apr. 2020), 1-15. 
[12] Bird, J., Montebruno, P. and Regan, T. 2017. Life in a slum: understanding living conditions in Nairobi's slums across time and space. Oxford Review of Economic Policy. 33, 3 (Jul. 2017), 496-520. DOI:https://doi.org/10.1093/oxrep/grx036.

[13] Borg, J., Larsson, S., Östergren, P.-O., Rahman, A.A., Bari, N. and Khan, A.N. 2012. Assistive technology use and human rights enjoyment: a cross-sectional study in Bangladesh. BMC International Health and Human Rights. 12, 1 (Sep. 2012), 18. DOI:https://doi.org/10.1186/1472-698X-12-18.

[14] Borg, J., Lindström, A. and Larsson, S. 2011. Assistive technology in developing countries: a review from the perspective of the Convention on the Rights of Persons with Disabilities. Prosthetics and Orthotics International. 35, 1 (Mar. 2011), 20-29. DOI:https://doi.org/10.1177/0309364610389351.

[15] Borg, J. and Östergren, P.-O. 2015. Users' perspectives on the provision of assistive technologies in Bangladesh: awareness, providers, costs and barriers. Disability and Rehabilitation: Assistive Technology. 10, 4 (Jul. 2015), 301-308. DOI:https://doi.org/10.3109/17483107.2014.974221.

[16] Branham, S.M. and Kane, S.K. 2015. Collaborative Accessibility: How Blind and Sighted Companions Co-Create Accessible Home Spaces. Proceedings of the 33rd Annual ACM Conference on Human Factors in Computing Systems (Seoul, Republic of Korea, Apr. 2015), 2373-2382.

[17] Branham, S.M. and Kane, S.K. 2015. The Invisible Work of Accessibility: How Blind Employees Manage Accessibility in Mixed-Ability Workplaces. Proceedings of the 17th International ACM SIGACCESS Conference on Computers \& Accessibility (Lisbon, Portugal, Oct. 2015), 163-171.

[18] Braun, V. and Clarke, V. 2006. Using thematic analysis in psychology. Qualitative Research in Psychology. 3, 2 (Jan. 2006), 77-101. DOI:https://doi.org/10.1191/1478088706qp063oa.

[19] Brewer, R.N., Austin, A.M. and Ellison, N.B. 2019. Stories from the Front Seat: Supporting Accessible Transportation in the Sharing Economy. Proceedings of the ACM on Human-Computer Interaction. 3, CSCW (Nov. 2019), 95:1-95:17. DOI:https://doi.org/10.1145/3359197.

[20] Davis, J., Crow, B. and Miles, J. 2012. Measuring water collection times in Kenyan informal settlements. Proceedings of the Fifth International Conference on Information and Communication Technologies and Development (Atlanta, Georgia, USA, Mar. 2012), 114-121.

[21] Dawe, M. 2007. Understanding mobile phone requirements for young adults with cognitive disabilities. Proceedings of the 9th international ACM SIGACCESS conference on Computers and accessibility (Tempe, Arizona, USA, Oct. 2007), 179-186.

[22] De', R., Pal, A., Sethi, R., Reddy, S.K. and Chitre, C. 2018. ICT4D research: a call for a strong critical approach. Information Technology for Development. 24, 1 (Jan. 2018), 63-94. DOI:https://doi.org/10.1080/02681102.2017.1286284.

[23] Desgroppes, A. and Taupin, S. 2011. Kibera: The Biggest Slum in Africa? Les Cahiers d'Afrique de l'Est / The East African Review. 44 (Sep. 2011), 23-33.

[24] Doughty, K. 2011. SPAs (smart phone applications)-a new form of assistive technology. Journal of assistive technologies. (2011). 
[25] Fok, D., Polgar, J.M., Shaw, L. and Jutai, J.W. 2011. Low vision assistive technology device usage and importance in daily occupations. Work. 39, 1 (Jan. 2011), 37-48. DOI:https://doi.org/10.3233/WOR-2011-1149.

[26] Gell, N.M., Wallace, R.B., LaCroix, A.Z., Mroz, T.M. and Patel, K.V. 2015. Mobility Device Use in Older Adults and Incidence of Falls and Worry About Falling: Findings from the 2011-2012 National Health and Aging Trends Study. Journal of the American Geriatrics Society. 63, 5 (2015), 853-859. DOI:https://doi.org/10.1111/jgs.13393.

[27] Ghosh, I. 2016. Contextualizing Intermediated Use in the Developing World: Findings from India \& Ghana. Proceedings of the 2016 CHI Conference on Human Factors in Computing Systems (San Jose, California, USA, May 2016), 355-359.

[28] GSMA 2019. Understanding the mobile disability gap.

[29] Hagan, M., Zhang, N. and Kaye, J. "Jofish" 2012. Safe mathare: a mobile system for women's safe commutes in the slums. Proceedings of the 14th international conference on Human-computer interaction with mobile devices and services companion (San Francisco, California, USA, Sep. 2012), 47-52.

[30] Hakobyan, L., Lumsden, J., O'Sullivan, D. and Bartlett, H. 2013. Mobile assistive technologies for the visually impaired. Survey of Ophthalmology. 58, 6 (Nov. 2013), 513-528. DOI:https://doi.org/10.1016/j.survophthal.2012.10.004.

[31] Heffernan, C., Lin, Y. and Thomson, K. 2016. Drawing from Development: Towards Unifying Theory and Practice of ICT4D. Journal of International Development. 28, 6 (2016), 902-918. D0I:https://doi.org/10.1002/jid.2882.

[32] Ho, M.R., Smyth, T.N., Kam, M. and Dearden, A. 2009. Human-computer interaction for development: The past, present, and future. Information Technologies \& International Development. 5, 4 (2009), pp-1.

[33] Holloway, C., Austin, V., Barbareschi, G. and Ramos, F. 2018. Scoping Research Report on Assistive Technology. On the road for universal assistive technology coverage. Prepared by the GDI Hub \& partners for the UK Department for International Development. Global Disability Innvoation Hub. (2018).

[34] Jack, W. and Suri, T. 2011. Mobile Money: The Economics of M-PESA. Technical Report \#16721. National Bureau of Economic Research.

[35] Kameswaran, V. and Hulikal Muralidhar, S. 2019. Cash, Digital Payments and Accessibility: A Case Study from Metropolitan India. Proceedings of the ACM on Human-Computer Interaction. 3, CSCW (Nov. 2019), 97:1-97:23. DOI:https://doi.org/10.1145/3359199.

[36] Kenya National Bureau of Statistics 2009. Kenya population and housing census. Kenya National Bureau of Statistics.

[37] Kibere, F.N. 2016. The Paradox of Mobility in the Kenyan ICT Ecosystem: An Ethnographic Case of How the Youth in Kibera Slum Use and Appropriate the Mobile Phone and the Mobile Internet. Information Technology for Development. 22, sup1 (Aug. 2016), 47-67. DOI:https://doi.org/10.1080/02681102.2016.1155144.

[38] King, J.A. and King, M.J. 2011. The Lived Experience of Families Living with Spinal Cord Disability inNortheast Thailand. Third World Quarterly. 32, 8 (Sep. 2011), 1475-1491. DOI:https://doi.org/10.1080/01436597.2011.614801. 
[39] Kovačič, P. and Lundine, J. 2013. Mapping Kibera: Empowering slum residents by ICT'. Bits and atoms: Information and communication technology in areas of limited statehood. (2013).

[40] MacLachlan, M. et al. 2018. Assistive technology policy: a position paper from the first global research, innovation, and education on assistive technology (GREAT) summit. Disability and Rehabilitation: Assistive Technology. 13, 5 (Jul. 2018), 454-466. DOI:https://doi.org/10.1080/17483107.2018.1468496.

[41] Mas, I. and Radcliffe, D. 2010. Mobile payments go viral: M-PESA in Kenya. (2010).

[42] Maslow, A.H. 1943. A theory of human motivation. Psychological review. 50, 4 (1943), 370.

[43] Matter, R., Harniss, M., Oderud, T., Borg, J. and Eide, A.H. 2017. Assistive technology in resource-limited environments: a scoping review. Disability and Rehabilitation: Assistive Technology. 12, 2 (Feb. 2017), 105-114. DOI:https://doi.org/10.1080/17483107.2016.1188170.

[44] May-Teerink, T. 1999. A survey of rehabilitative services and people coping with physical disabilities in Uganda, East Africa. International journal of rehabilitation research. Internationale Zeitschrift fur Rehabilitationsforschung. Revue internationale de recherches de readaptation. 22, 4 (1999), 311-316.

[45] Mbiti, I. and Weil, D.N. 2015. Mobile Banking: The Impact of M-Pesa in Kenya. African Successes, Volume III: Modernization and Development. (Sep. 2015), 247-293.

[46] McSweeney, E. and Gowran, R.J. 2019. Wheelchair service provision education and training in low and lower middle income countries: a scoping review. Disability and Rehabilitation: Assistive Technology. 14, 1 (Jan. 2019), 33-45. DOI:https://doi.org/10.1080/17483107.2017.1392621.

[47] Meredith, T. and MacDonald, M. 2017. Community-supported slum-upgrading: Innovations from Kibera, Nairobi, Kenya. Habitat International. 60, (Feb. 2017), 1-9. DOI:https://doi.org/10.1016/j.habitatint.2016.12.003.

[48] Mia Mingus 2010. Interdependency (exerpts from several talks). Leaving Evidence.

[49] Mitra, S., Posarac, A. and Vick, B. 2013. Disability and Poverty in Developing Countries: A Multidimensional Study. World Development. 41, (Jan. 2013), 1-18. DOI:https://doi.org/10.1016/j.worlddev.2012.05.024.

[50] Morawczynski, O. and Pickens, M. 2009. Poor people using mobile financial services: observations on customer usage and impact from M-PESA. (2009).

[51] Mukherjee, G. and Samanta, A. 2005. Wheelchair charity: A useless benevolence in community-based rehabilitation. Disability and Rehabilitation. 27, 10 (May 2005), 591-596. DOI:https://doi.org/10.1080/09638280400018387.

[52] Mutisya, E. and Yarime, M. 2011. Understanding the grassroots dynamics of slums in Nairobi: the dilemma of Kibera informal settlements. Int Trans J Eng Manag Appl Sci Technol. 2, 2 (2011), 197-213.

[53] Pal, J., Chandra, P., O'Neill, T., Youngman, M., Jones, J., Song, J.H., Strayer, W. and Ferrari, L. 2016. An Accessibility Infrastructure for the Global South. Proceedings of the Eighth International Conference on Information and 
Communication Technologies and Development (Ann Arbor, MI, USA, Jun. 2016), $1-11$.

[54] Pal, J., Viswanathan, A., Chandra, P., Nazareth, A., Kameswaran, V., Subramonyam, H., Johri, A., Ackerman, M.S. and O'Modhrain, S. 2017. Agency in Assistive Technology Adoption: Visual Impairment and Smartphone Use in Bangalore. Proceedings of the 2017 CHI Conference on Human Factors in Computing Systems (New York, NY, USA, 2017), 5929-5940.

[55] Pearlman, J. 2006. Review session: Review of literature on wheelchairs for developing countries \& Review of wheelchair provision in developing countries. Consensus Conference on Wheelchairs for Developing Countries (2006), 6-11.

[56] Perrier, T., Dell, N., DeRenzi, B., Anderson, R., Kinuthia, J., Unger, J. and JohnStewart, G. 2015. Engaging Pregnant Women in Kenya with a Hybrid ComputerHuman SMS Communication System. Proceedings of the 33rd Annual ACM Conference on Human Factors in Computing Systems (Seoul, Republic of Korea, Apr. 2015), 1429-1438.

[57] Reyes-Cruz, G., Fischer, J.E. and Reeves, S. 2020. Reframing Disability as Competency: Unpacking Everyday Technology Practices of People with Visual Impairments. Proceedings of the 2020 CHI Conference on Human Factors in Computing Systems (Honolulu, HI, USA, Apr. 2020), 1-13.

[58] Ríos, M.I.H., Silva, S.S., Díaz, E.I.R. and Monterrosa, N.T. 2017. YAMI: Auxiliary Complement to Enable Visually Impaired People to Use Mobile Devices. Proceedings of the 8th Latin American Conference on Human-Computer Interaction (New York, NY, USA, 2017), 24:1-24:4.

[59] Sambasivan, N., Cutrell, E., Toyama, K. and Nardi, B. 2010. Intermediated Technology Use in Developing Communities. Proceedings of the SIGCHI Conference on Human Factors in Computing Systems (New York, NY, USA, 2010), 2583-2592.

[60] Sambasivan, N., Rangaswamy, N., Cutrell, E. and Nardi, B. 2009. Ubicomp4D: infrastructure and interaction for international development--the case of urban indian slums. Proceedings of the 11th international conference on Ubiquitous computing (Orlando, Florida, USA, Sep. 2009), 155-164.

[61] Sambasivan, N. and Smyth, T. 2010. The human infrastructure of ICTD. Proceedings of the 4th ACM/IEEE international conference on information and communication technologies and development (2010), 1-9.

[62] Scherer, M.J. 2005. Living in the state of stuck: How assistive technology impacts the lives of people with disabilities. Brookline Books.

[63] Shore, S. and Juillerat, S. 2012. The impact of a low cost wheelchair on the quality of life of the disabled in the developing world. Medical Science Monitor : International Medical Journal of Experimental and Clinical Research. 18, 9 (Sep. 2012), CR533-CR542. DOI:https://doi.org/10.12659/MSM.883348.

[64] Soro, A., Brereton, M., Sitbon, L., Ambe, A.H., Taylor, J.L. and Wilson, C. 2019. Beyond Independence: Enabling Richer Participation through Relational Technologies. Proceedings of the 31st Australian Conference on HumanComputer-Interaction (Fremantle, WA, Australia, Dec. 2019), 149-160. 
[65] de Souza e Silva, A., Sutko, D.M., Salis, F.A. and de Souza e Silva, C. 2011. Mobile phone appropriation in the favelas of Rio de Janeiro, Brazil. New Media \& Society. 13, 3 (May 2011), 411-426. DOI:https://doi.org/10.1177/1461444810393901.

[66] Star, S.L. 1999. The ethnography of infrastructure. American behavioral scientist. 43, 3 (1999), 377-391.

[67] Storer, K.M., Judge, T.K. and Branham, S.M. 2020. "All in the Same Boat": Tradeoffs of Voice Assistant Ownership for Mixed-Visual-Ability Families. Proceedings of the 2020 CHI Conference on Human Factors in Computing Systems (Honolulu, HI, USA, Apr. 2020), 1-14.

[68] Stumbo, N.J., Martin, J.K. and Hedrick, B.N. 2009. Assistive technology: Impact on education, employment, and independence of individuals with physical disabilities. Journal of Vocational Rehabilitation. 30, 2 (Jan. 2009), 99-110. DOI:https://doi.org/10.3233/JVR-2009-0456.

[69] Swahn, M.H., Braunstein, S. and Kasirye, R. 2014. Demographic and Psychosocial Characteristics of Mobile Phone Ownership and Usage among Youth Living in the Slums of Kampala, Uganda. Western Journal of Emergency Medicine. 15, 5 (Aug. 2014), 600-603. DOI:https://doi.org/10.5811/westjem.2014.4.20879.

[70] Tigwell, G.W., Sarsenbayeva, Z., Gorman, B.M., Flatla, D.R., Goncalves, J., Yesilada, Y. and Wobbrock, J.0. 2019. Addressing the Challenges of Situationally-Induced Impairments and Disabilities in Mobile Interaction. Extended Abstracts of the 2019 CHI Conference on Human Factors in Computing Systems (Glasgow, Scotland Uk, May 2019), 1-8.

[71] Toro, M.L., Garcia, Y., Ojeda, A.M., Dausey, D.J. and Pearlman, J. 2013. Quantitative exploratory evaluation of the frequency, causes and consequences of rehabilitation wheelchair breakdowns delivered at a paediatric clinic in Mexico. (2013).

[72] Toyama, K. 2015. Geek heresy: Rescuing social change from the cult of technology. PublicAffairs.

[73] Toyama, K. 2011. Technology as amplifier in international development. Proceedings of the 2011 iConference (Seattle, Washington, USA, Feb. 2011), 7582.

[74] Turok, I. and Borel-Saladin, J. 2018. The theory and reality of urban slums: Pathways-out-of-poverty or cul-de-sacs? Urban Studies. 55, 4 (Mar. 2018), 767789. DOI:https://doi.org/10.1177/0042098016671109.

[75] Vashistha, A., Brady, E., Thies, W. and Cutrell, E. 2014. Educational Content Creation and Sharing by Low-Income Visually Impaired People in India. Proceedings of the Fifth ACM Symposium on Computing for Development (San Jose, California, USA, Dec. 2014), 63-72.

[76] Vashistha, A., Cutrell, E., Dell, N. and Anderson, R. 2015. Social Media Platforms for Low-Income Blind People in India. Proceedings of the 17th International ACM SIGACCESS Conference on Computers \& Accessibility (New York, NY, USA, 2015), 259-272.

[77] Vergunst, R., Swartz, L., Mji, G., MacLachlan, M. and Mannan, H. 2015. 'You must carry your wheelchair' - barriers to accessing healthcare in a South African 
rural area. Global Health Action. 8, 1 (Dec. 2015), 29003.

DOI:https://doi.org/10.3402/gha.v8.29003.

[78] Visagie, S., Mlambo, T., Van der Veen, J., Nhunzvi, C., Tigere, D. and Scheffler, E. 2015. Is any wheelchair better than no wheelchair? A Zimbabwean perspective. African Journal of Disability. 4, 1 (2015).

[79] World Health Organization 2006. Disability and rehabilitation WHO action plan 2006-2011. Geneva, Switzerland: World Health Organization. (2006), 1-7.

[80] World Health Organization 2017. Global priority research agenda for improving access to high-quality affordable assistive technology. World Health Organization.

[81] World Health Organization 2016. Priority assistive products list.

[82] World Health Organization 2011. World Report on Disability.

[83] Wyche, S. 2015. Exploring Mobile Phone and Social Media Use in a Nairobi Slum: A Case for Alternative Approaches to Design in ICTD. Proceedings of the Seventh International Conference on Information and Communication Technologies and Development (New York, NY, USA, 2015), 12:1-12:8.

[84] Wyche, S., Dillahunt, T.R., Simiyu, N. and Alaka, S. 2015. "If god gives me the chance i will design my own phone": exploring mobile phone repair and postcolonial approaches to design in rural Kenya. Proceedings of the 2015 ACM International Joint Conference on Pervasive and Ubiquitous Computing (Osaka, Japan, Sep. 2015), 463-473.

[85] Wyche, S.P., Forte, A. and Yardi Schoenebeck, S. 2013. Hustling online: understanding consolidated facebook use in an informal settlement in Nairobi. Proceedings of the SIGCHI Conference on Human Factors in Computing Systems (Paris, France, Apr. 2013), 2823-2832.

[86] Wyche, S.P. and Murphy, L.L. 2012. "Dead China-make" phones off the grid: investigating and designing for mobile phone use in rural Africa. Proceedings of the Designing Interactive Systems Conference (Newcastle Upon Tyne, United Kingdom, Jun. 2012), 186-195.

[87] Zakerhaghighi, K., Khanian, M. and Gheitarani, N. 2015. Subjective quality of life; assessment of residents of informal settlements in Iran (a case study of Hesar Imam Khomeini, Hamedan). Applied Research in Quality of Life. 10, 3 (2015), 419-434. 